\title{
Anterior Shoulder Dislocation Complicated by Hill-Sachs Lesion
}

\author{
Nofel Iftikhar ${ }^{1}$, Thor S. Stead ${ }^{2}$, Latha Ganti ${ }^{3,4,5,6}$, Ilya Aleksandrovskiy ${ }^{5}$, Frank Fraunfelter ${ }^{5}$ \\ 1. Emergency Medicine, Trinity Preparatory School, Winter Park, USA 2. Medicine, Warren Alpert Medical School, \\ Providence, USA 3. Emergency Medicine, Envision Physician Services, Plantation, USA 4. Emergency Medicine, \\ University of Central Florida College of Medicine, Orlando, USA 5. Emergency Medicine, Ocala Regional Medical \\ Center, Ocala, USA 6. Emergency Medicine, HCA Healthcare Graduate Medical Education Consortium Emergency \\ Medicine Residency Program of Greater Orlando, Olrando, USA
}

Corresponding author: Latha Ganti, latha.ganti@ucf.edu

\begin{abstract}
We present the case of a 60-year-old woman with a Hill-Sachs lesion caused by an anterior shoulder dislocation (SD) as a result of her falling on her left shoulder at a local restaurant. While the diagnosis of an anterior SD is commonplace, the involvement of a Hill-Sachs lesion can complicate the treatment needed to manage the SD. Crucial aspects of treatment include performing closed reduction followed by acute immobilization in a timely manner and prompt consultation with orthopedic surgery.
\end{abstract}

Review began 07/27/2021 Review ended 07/28/2021 Published 08/05/2021

(c) Copyright 2021 Iftikhar et al. This is an open access article distributed under the terms of the Creative Commons Attribution License CC-BY 4.0., which permits unrestricted use, distribution, and reproduction in any medium, provided the original author and source are credited.
Categories: Emergency Medicine, Orthopedics, Anatomy

Keywords: anterior dislocation, shoulder dislocation, humeral head, closed reduction, hill-sachs lesion

\section{Introduction}

Shoulder dislocations (SDs) are a relatively common complaint in the Emergency Department (ED). Fifty percent of all reported joint dislocations are classified as SDs [1]. SDs are divided into two categories, anterior and posterior, with anteriorly dislocated shoulders accounting for the majority (95\%-97\%) of cases [2]. Anterior SDs are identified by the displacement of the head of the humerus bone in front of the glenoid [3-5]. A Hill-Sachs lesion is a compression injury in the humeral head, which is often caused by the dislocation of the glenoid rim such as during an anterior SD [6]. Because of this, Hill-Sachs lesions are primarily discovered during the $\mathrm{x}$-rays obtained in identifying an anterior SD [7]. The authors describe a case of a Hill-Sachs lesion coupled with an anterior SD and the treatment provided.

\section{Case Presentation}

A 60-year-old woman complaining of severe pain in her left shoulder presented to the ED. The patient had fallen onto her shoulder at a local restaurant. She did not hit her head in the fall but did hit the tip of her nose. Her nose was bruised, but she did not have any difficulty breathing through it. The patient's vitals were as follows: $\mathrm{O}_{2}$ saturation $97 \%$ on room air, blood pressure $190 / 101 \mathrm{mmHg}$, mean arterial pressure $130 \mathrm{mmHg}$, temperature $97.4^{\circ} \mathrm{F}$, pulse 87 beats per minute, and respiratory rate 16 breaths per minute. Throughout the examination, the patient was alert and answering questions but was clearly in pain. The left arm was slightly abducted and externally rotated. There was an apparent defect when compared to the right shoulder. The patient had good radial, brachioradialis, and axillary pulses. The skin was warm and dry. Although an anterior SD was evident on clinical examination, the patient was sent to radiology for an $\mathrm{x}$-ray to look for any associated fractures. The $\mathrm{x}$-ray featured a clearly anteriorly dislocated shoulder associated with a HillSachs lesion on the humeral head (Figure 1). 


\section{Cureus}

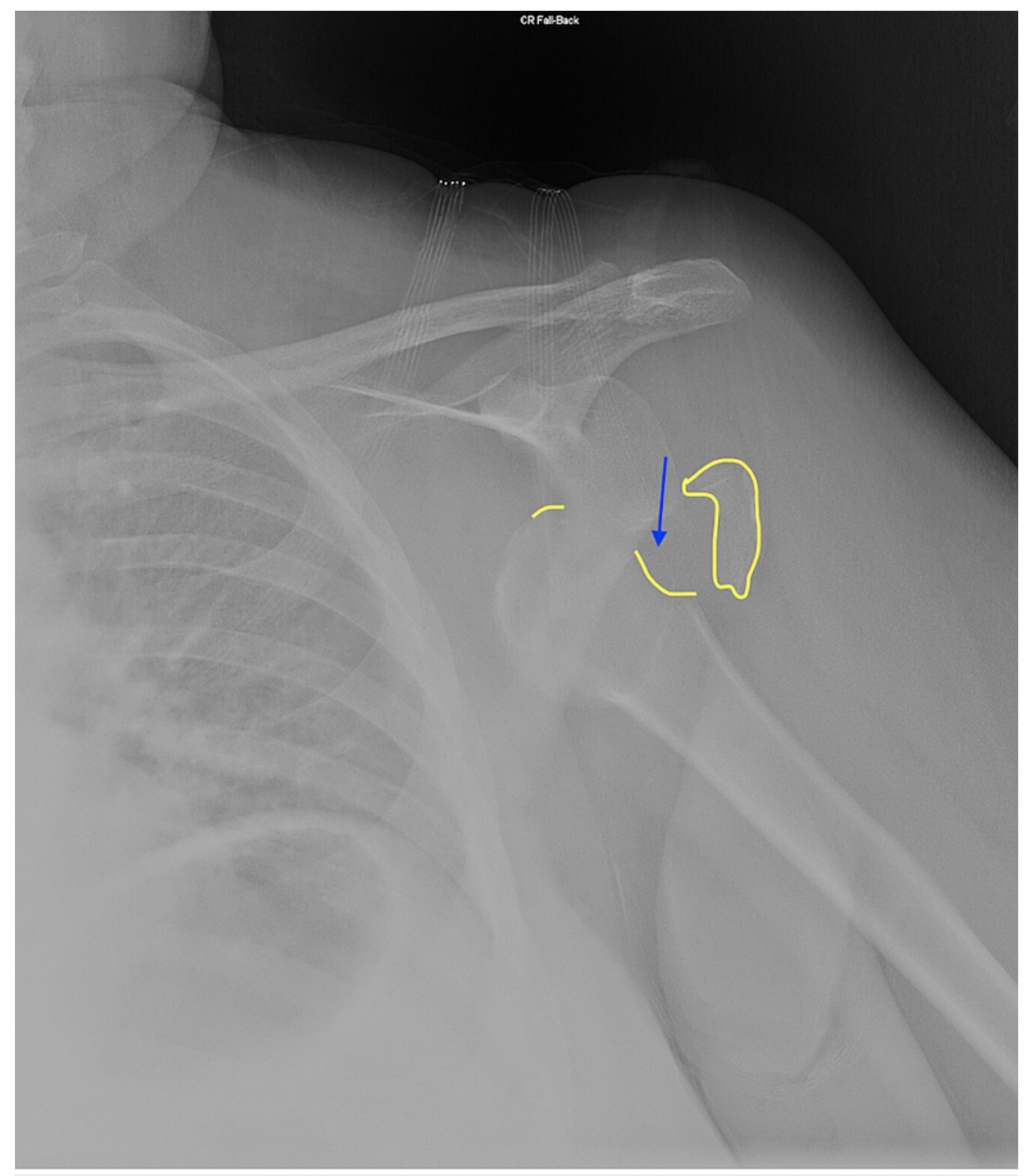

FIGURE 1: Patient's shoulder radiograph pre-reduction with an outline of the Hill-Sachs fracture and an arrow pointing toward the Hill-Sachs lesion on the humeral head. Outlined in yellow is a loose fracture fragment.

Orthopedic surgery was consulted and recommended closed reduction in the ED with orthopedic office follow-up. Following informed consent, the patient underwent conscious sedation with intravenous ketamine and etomidate. The patient tolerated the procedure well, and the procedure was a success. The post-reduction x-rays depict regular alignment between the humeral head and the glenoid (Figure 2). 


\section{Cureus}

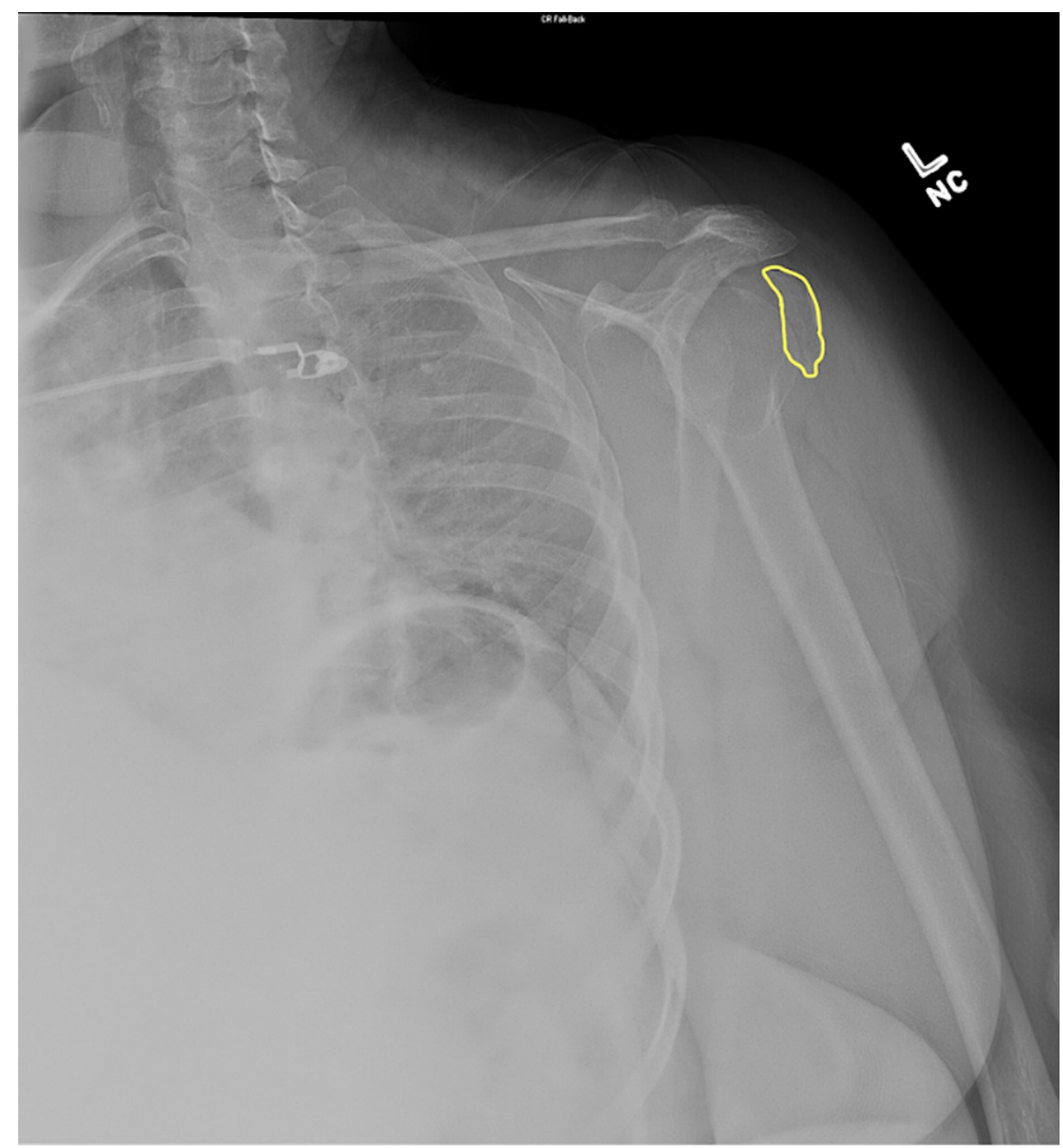

FIGURE 2: Patient's shoulder radiograph post-reduction with an outline of the Hill-Sachs fracture.

Post-reduction, the patient could fully range her shoulder and there was no longer a void in the shoulder capsule. Sensation over the deltoid was intact. The patient's vital signs following the reduction were $\mathrm{O}_{2}$ saturation $99 \%$ on room air, blood pressure $148 / 97 \mathrm{mmHg}$ (this slightly elevated blood pressure is easily explained by the patient's pre-existing hypertension), mean arterial pressure $114 \mathrm{mmHg}$, temperature $98.4^{\circ} \mathrm{F}$, pulse 88 beats per minute, and respiratory rate 16 breaths per minute. The patient's arm was placed in a sling and the patient was discharged to follow up with orthopedics.

\section{Discussion}

Anterior SDs are primarily caused by forced abduction, external rotation, and hyperextension, all of which are expected consequences of patients falling on their outstretched arm or their shoulder, injuries sustained in sports, or trauma (Figure 3) [8]. 


\section{Cureus}

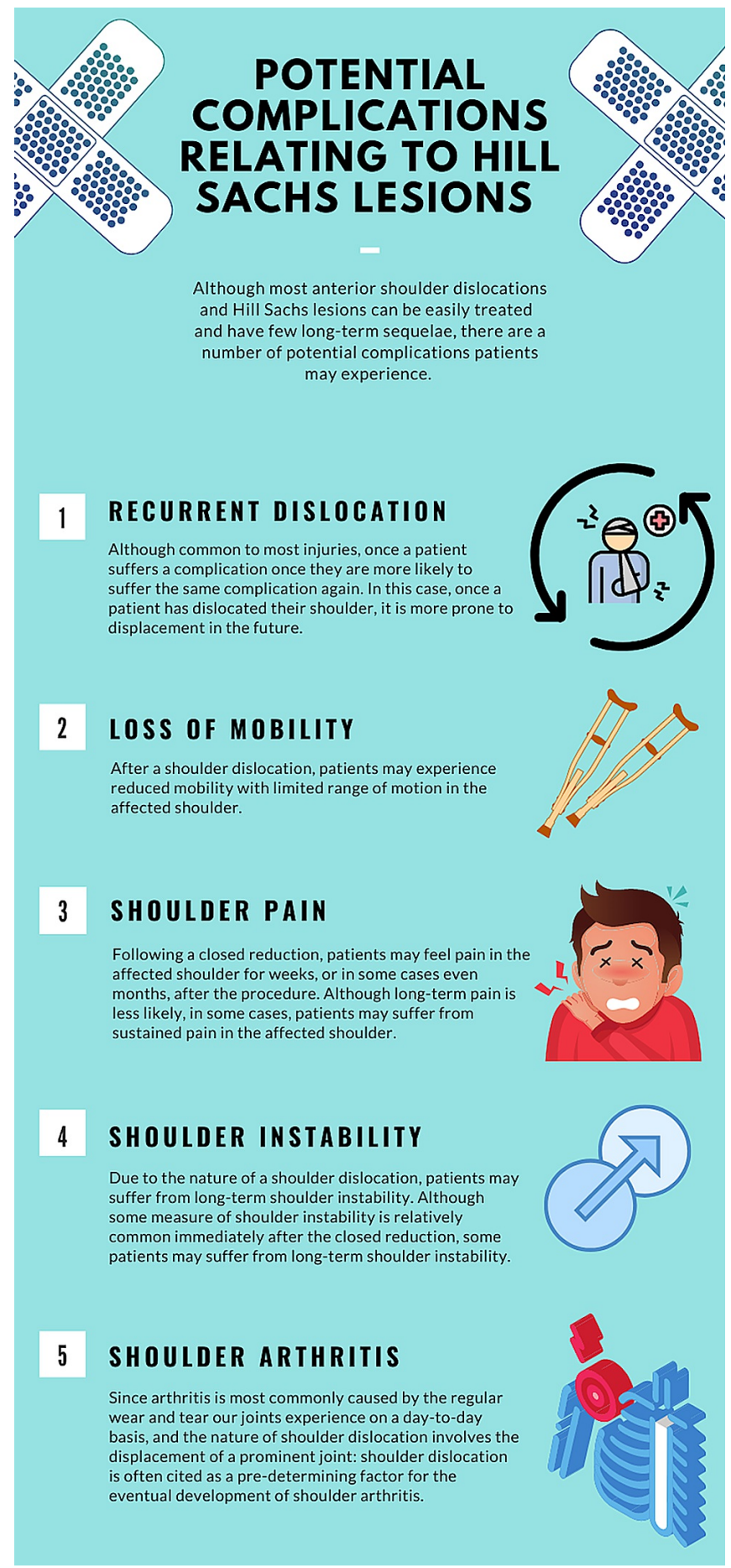

FIGURE 3: Infographic summarizing potential long-term complications associated with Hill-Sachs lesion.

Symptoms of anterior SD include severe pain, numbness, deformity, and swelling. X-ray imaging is sufficient to identify most anterior SDs and any associated fractures. Diagnosis can also be made at the bedside more swiftly with the point of care ultrasound (POCUS). POCUS is slowly gaining traction in the medical community, especially in the ED, as it is seen as more convenient (saving time), less expensive, noninvasive, and does not involve radiation. Although in the past, shoulder radiography was seen as the preferred method of diagnosing SDs, in the present day, the sensitivity and specificity of POCUS in identifying SDs is $100 \%$. Much like the diagnosis of an SD via a shoulder radiograph, POCUS also features a picture of the shoulder joint with the humeral head clearly misaligned relative to the glenoid [9-12]. An anterior SD is identified by a humeral head that is "deeper" than the adjacent glenoid fossa. 
for complete healing [3]. However, the standard of care can vary for anterior SDs complicated by a Hill-Sachs lesion. Treatment of anterior SDs with accompanying Hill-Sachs lesions is primarily dependent on the size of the lesion on the head of the humerus. If the lesion occupies less than $20 \%$ of the head of the humerus, the standard treatment of immobilization and physical therapy can be executed. If it occupies more than $20 \%$ of the head of the humerus; however, treatment options include bone augmentation, remplissage, disimpaction, and limited resurfacing [13]. The process of bone augmentation is primarily divided into two procedures: glenoid augmentation and humeral head augmentation. Glenoid augmentations involve the lengthening of the articular arc of the glenoid via allograft tissues, and humeral head augmentations involve the filling of the Hill-Sachs lesion to restore regular anatomy. Another procedure, remplissage, is meant to convert an intra-articular defect into an extra-articular defect using soft tissue to prevent engagement of the Hill-Sachs lesion. Disimpaction, another treatment for Hill-Sachs, is focused on restoring the normal anatomy of the humeral head by elevating the fracture itself and reinforcing it with a bone graft. Limited resurfacing, much like glenoid bone augmentation, defines the procedure of installing a metal implant in hopes of restoring the humeral head articular arc. Although there are a number of procedures orthopedic surgeons use to treat Hill-Sachs deformities, the ones mentioned above are the most commonly performed [13-16]. Most patients will not suffer complications. However, possible complications related to the HillSachs lesions are discussed in Figure $3[4,17]$.

Another way to categorize the size of Hill-Sachs lesions is based on depth. The depth of the lesion reflects the amount of damage to the opposite side of the joint - the anterior capsule and the labrum [18]. If depth is less than $1 / 8$, then closed reduction of the SD is appropriate and no specific treatment for the Hill-Sachs lesion is necessary. If the depth is between $1 / 8$ and $1 / 4$, remplissage is typically performed. Lesions larger than $1 / 4$ are rare and are typically treated with disimpaction, where the defect is filled in with bone or sometimes a metal implant [19].

\section{Conclusions}

Anterior SDs can sometimes be complicated by the co-occurrence of a Hill-Sachs lesion. Small lesions can be managed with routine closed reduction, shoulder sling, and orthopedic follow-up. Larger lesions may need further therapy. Some patients will have long-term complications related to the Hill-Sachs lesion.

\section{Additional Information \\ Disclosures}

Human subjects: Consent was obtained or waived by all participants in this study. HCA Centralized Algorithms for Research Rules on IRB Exemptions (CARRIE)/ IRB manager issued approval 2021-523. HCA Centralized Algorithms for Research Rules on IRB Exemptions (CARRIE)/IRB manager issued approval [2021-523]. Based on the information provided and attested as true, the research plan described does not require IRB oversight. This is because you are either a) not engaging in research with human subjects as defined by federal regulations; b) engaging in research with human subjects deemed excluded from IRB oversight per 45CFR46.102(1); or c) engaging in research with sufficient human subject protections in the design to meet one or more IRB exemption criteria set forth in 45CFR46.104. Conflicts of interest: In compliance with the ICMJE uniform disclosure form, all authors declare the following: Payment/services info: All authors have declared that no financial support was received from any organization for the submitted work. Financial relationships: All authors have declared that they have no financial relationships at present or within the previous three years with any organizations that might have an interest in the submitted work. Other relationships: All authors have declared that there are no other relationships or activities that could appear to have influenced the submitted work.

\section{Acknowledgements}

This research was supported (in whole or in part) by HCA Healthcare and/or an HCA Healthcare affiliated entity. The views expressed in this publication represent those of the author(s) and do not necessarily represent the official views of HCA Healthcare or any of its affiliated entities.

\section{References}

1. Abrams R, Akbarnia H: Shoulder Dislocations Overview. StatPearls Publishing, Treasure Island, FL; 2021.

2. Brady WJ, Knuth CJ, Pirrallo RG: Bilateral inferior glenohumeral dislocation: luxatio erecta, an unusual presentation of a rare disorder. J Emerg Med. 1995, 13:37-42. 10.1016/0736-4679(94)00110-3

3. Radiopedia: anterior shoulder dislocation. (2020). Accessed: July 13, 2021: https://radiopaedia.org/articles/anterior-shoulder-dislocation.

4. Cutts S, Prempeh M, Drew S: Anterior shoulder dislocation. Ann R Coll Surg Engl. 2009, 91:2-7. 10.1308/003588409X359123

5. Physiopedia: shoulder dislocation. (2020). Accessed: July 13, 2021: https://www.physiopedia.com/Shoulder_Dislocation.

6. Physiopedia: Hill Sachs lesion. (2020). Accessed: July 13, 2021: https://www.physiopedia.com/Hill_Sachs_Lesion.

7. Radiopedia: Hill-Sachs defect. (2020). Accessed: July 13, 2021: https://radiopaedia.org/articles/hill-sachsdefect. 


\section{Cureus}

8. Zacchilli MA, Owens BD: Epidemiology of shoulder dislocations presenting to emergency departments in the United States. J Bone Joint Surg Am. 2010, 92:542-9. 10.2106/JBJS.I.00450

9. Secko MA, Reardon L, Gottlieb M, Morley EJ, Lohse MR, Thode HC Jr, Singer AJ: Musculoskeletal ultrasonography to diagnose dislocated shoulders: a prospective cohort. Ann Emerg Med. 2020, 76:119-28. 10.1016/j.annemergmed.2020.01.008

10. Gottlieb M, Holladay D, Peksa GD: Point-of-care ultrasound for the diagnosis of shoulder dislocation: a systematic review and meta-analysis. Am J Emerg Med. 2019, 37:757-61. 10.1016/j.ajem.2019.02.024

11. Akyol C, Gungor F, Akyol AJ, et al.: Point-of-care ultrasonography for the management of shoulder dislocation in ED. Am J Emerg Med. 2016, 34:866-70. 10.1016/j.ajem.2016.02.006

12. Hendey GW: Necessity of radiographs in the emergency department management of shoulder dislocations Ann Emerg Med. 2000, 36:108-13. 10.1067/mem.2000.108314

13. Cho NS, Hwang SP: Humeral head bone defects in anterior shoulder instability: preoperative assessment and surgical management for Hill-Sachs lesion. Arthrosc Orthop Sports Med. 1, 2014:82-90. 10.14517/aosm13016

14. Hurley ET, Toale JP, Davey MS, Colasanti CA, Pauzenberger L, Strauss EJ, Mullett H: Remplissage for anterior shoulder instability with Hill-Sachs lesions: a systematic review and meta-analysis. J Shoulder Elbow Surg. 2020, 29:2487-94. 10.1016/j.jse.2020.06.021

15. Streubel PN, Krych AJ, Simone JP, et al.: Anterior glenohumeral instability: a pathology-based surgical treatment strategy. J Am Acad Orthop Surg. 2014, 22:283-94. 10.5435/JAAOS-22-05-283

16. Itoi E: 'On-track' and 'off-track' shoulder lesions . EFORT Open Rev. 2017, 2:343-51. 10.1302/2058 5241.2.170007

17. Khiami F, Gérometta A, Loriaut P: Management of recent first-time anterior shoulder dislocations . Orthop Traumatol Surg Res. 2015, 101:S51-7. 10.1016/j.otsr.2014.06.027

18. Hill-Sachs lesion. (2020). Accessed: July 28, 2021: https://www.shoulderdoc.co.uk/article/1470.

19. Kralinger FS, Golser K, Wischatta R, Wambacher M, Sperner G: Predicting recurrence after primary anterior shoulder dislocation. Am J Sports Med. 2002, 30:116-20. 10.1177/03635465020300010501 